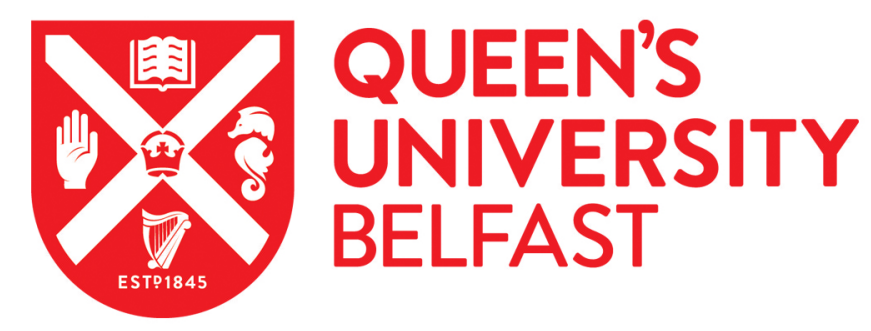

\title{
Dynamic model of supercritical Organic Rankine Cycle waste heat recovery system for internal combustion engine
}

Chowdhury, J. I., Nguyen, B. K., \& Thornhill, D. (2017). Dynamic model of supercritical Organic Rankine Cycle waste heat recovery system for internal combustion engine. International Journal of Automotive Technology, 18(4), 589-601. https://doi.org/10.1007/s12239-017-0059-8

Published in:

International Journal of Automotive Technology

Document Version:

Peer reviewed version

Queen's University Belfast - Research Portal:

Link to publication record in Queen's University Belfast Research Portal

Publisher rights

(C) 2016 KSAE.

The final publication is available at Springer via http://dx.doi.org/[insert DOI

\section{General rights}

Copyright for the publications made accessible via the Queen's University Belfast Research Portal is retained by the author(s) and / or other copyright owners and it is a condition of accessing these publications that users recognise and abide by the legal requirements associated with these rights.

Take down policy

The Research Portal is Queen's institutional repository that provides access to Queen's research output. Every effort has been made to ensure that content in the Research Portal does not infringe any person's rights, or applicable UK laws. If you discover content in the Research Portal that you believe breaches copyright or violates any law, please contact openaccess@qub.ac.uk. 


\title{
DYNAMIC MODEL OF SUPERCRITICAL ORGANIC RANKINE CYCLE WASTE HEAT RECOVERY SYSTEM FOR INTERNAL COMBUSTION ENGINE
}

\author{
J. I. CHOWDHURY, B. K. NGUYEN* and D. THORNHILL \\ School of Mechanical and Aerospace Engineering, Queen’s University Belfast, Belfast, BT9 5AH, UK \\ (Received date $\quad$; Revised date $\quad$;Accepted date $\quad$ ) * Please leave blank
}

\begin{abstract}
The supercritical Organic Rankine Cycle (ORC) for the Waste Heat Recovery (WHR) from Internal Combustion (IC) engines has been a growing research area in recent years, driven by the aim to enhance the thermal efficiency of the ORC and engine. Simulation of a supercritical ORC-WHR system before a real-time application is important as high pressure in the system may lead to concerns about safety and availability of components. In the ORC-WHR system, the evaporator is the main contributor to thermal inertia of the system and is considered to be the critical component since the heat transfer of this device influences the efficiency of the system. Since the thermophysical properties of the fluid at supercritical pressures are dependent on temperature, it is necessary to consider the variations in properties of the working fluid. The well-known Finite Volume (FV) discretization method is generally used to take those property changes into account. However, a FV model of the evaporator in steady state condition cannot be used to predict the thermal inertia of the cycle when it is subjected to transient heat sources. In this paper, a dynamic FV model of the evaporator has been developed and integrated with other components in the ORC-WHR system. The stability and transient responses along with the performance of the ORC-WHR system for the transient heat source are investigated and are also included in this paper.
\end{abstract}

KEY WORDS: Dynamic model, Finite volume, Organic Rankine Cycle, Supercritical evaporator, Transient heat source, Waste heat recovery

\section{NOMENCLATURE}

A heat transfer area, $\mathrm{m}^{2}$

$\mathrm{C}_{\mathrm{p}}$ specific heat capacity, kJ/kg.K

D hydraulic diameter, $\mathrm{m}$

$\mathrm{H}$ specific enthalpy, $\mathrm{kJ} / \mathrm{kg}$

$\mathrm{h}$ heat transfer coefficient, $\mathrm{kW} / \mathrm{m}^{2} \mathrm{~K}$

$\mathrm{K}$ thermal conductivity, $\mathrm{kW} / \mathrm{m} . \mathrm{K}$

$\mathrm{L} \quad$ plate length, $\mathrm{m}$

m mass, $\mathrm{kg}$

$\dot{\mathrm{m}}$ mass flow rate, $\mathrm{kg} / \mathrm{s}$

$\mathrm{N}_{\mathrm{p}}$ rotational speed, RPM

$\mathrm{N}$ number of segments

$\mathrm{n} \quad$ number of plates

$\mathrm{Nu} \quad$ Nusselt number

$\mathrm{P}$ pressure, $\mathrm{kPa}$

Pr Prandtl number

\footnotetext{
* Corresponding author. e-mail: b.nguyen@qub.ac.uk
}

Q heat transfer rate, $\mathrm{kW}$

Re Reynolds number

$\mathrm{T}$ temperature, $\mathrm{K}$

$\mathrm{V}$ volume, $\mathrm{m}^{3}$ or velocity, $\mathrm{m} / \mathrm{s}$

$\mathrm{W}$ power output, $\mathrm{kW}$

w plate width, $\mathrm{m}$ or specific work, $\mathrm{kW} / \mathrm{kg}$

$\mu \quad$ dynamic viscosity, Pa.s

$\rho$ density, $\mathrm{kg} / \mathrm{m}^{3}$

$\eta \quad$ efficiency

$v \quad$ specific volume, $\mathrm{m}^{3} / \mathrm{kg}$

\section{SUBSCRIPTS}

ac accumulator

b bulk

cy cycle

con condenser

ev evaporator

exp expander

$\mathrm{h}$ heat source

hr heat recovery

i inlet 
isen isentropic

j segments notation

$1 \quad$ liquid

o outlet

p pump

pc pseudo-critical

$\mathrm{r}$ refrigerant

ref reference

w wall

\section{ABBREVIATIONS}

FV Finite Volume

IC Internal Combustion

NIST National Institute of Standards and Technology

ORC Organic Rankine Cycle

PCM Phase Change Material

RPM Revolutions per Minute

TEG Thermoelectric Generator

WHR Waste Heat Recovery

\section{INTRODUCTION}

The global energy consumption in the form of heat, electricity and mechanical power has increased by over $50 \%$ in the previous decade. Around $86 \%$ of this energy demand is fulfilled from fossil fuels (International Energy Statistics, 2016). Over the last few decades, the prices of fossil fuels have also increased by around three times (Chen et al., 2014) and, as a result, energy generated from fossil fuel has become expensive. Moreover, the greenhouse gases and pollutant emissions due to the burning of fossil fuels have an unavoidable effect on the environment and Ozone-layer depletion. Both the higher fuel cost and environmental issues have driven recent research to emphasize the development and utilization of alternative sources of energy, such as geothermal, solar heat and various types of waste heat, etc. (Molina-Thierry and Flores-Tlacuahuac, 2015). Among these alternative sources, the waste heat from internal combustion (IC) engine has a significant importance to the energy conversion efficiency of the engine. A typical IC engine with diesel fuel, at its best operating condition, can convert a maximum of $45 \%$ of fuel energy into shaft energy; while the gasoline engine converts a maximum of 35\% (Boretti, 2012). The rest of the fuel's energy is lost to the exhaust and cooling systems. The waste heat from IC engines are low to medium grade energy, and one popular method of using this heat is to integrate a waste heat recovery (WHR) system at the bottom of the main engine system. The WHR system converts the exhaust or coolant heat into either mechanical rotation or electrical power, which increases the thermal efficiency and, as a result, reduces the fuel consumption of the engine (Glover et al., 2014; Imran et al., 2015). Within the WHR system, three technologies were considered: Thermoelectric Generator (TEG), Organic Rankine Cycle (ORC) and Phase Change Material (PCM) engine system; these can be found in the literature (Johansson and Söderström, 2014). The selection of appropriate technology for the WHR is dependent on the type of heat source, the heat transfer requirement, and the application, etc. The conversion efficiency of the PCM, TEG and ORC are, generally, up to $2.5 \%, 5 \%$ and $16 \%$, respectively (Johansson and Söderström, 2014). Among these methods, the ORC is well established and preferred for waste heat recovery from low and medium grade heat sources because of its high thermal efficiency, low weight, small volume, simplicity, availability of components and compatibility with a range of heat sources (Gao et al., 2012; Shu et al., 2014; Johansson and Söderström, 2014).

The ORC is a fluid-based power cycle that consists of four basic components: pump, evaporator, expander, and condenser. The working fluids used in the ORC are organic substances (i.e., hydrocarbons or refrigerants) instead of water which is normal in the traditional Rankine cycle. Compared to water, the thermo-physical properties of the organic fluid are more suitable to use in a WHR system with a low to medium grade heat source and can generate a power output from a few $\mathrm{kW}$ to $200 \mathrm{~kW}$ (Bamgbopa and Uzgoren, 2013; Zhang et al., 2013).

Selection of the working fluid and operating condition of the ORC is always critical in the design of WHR systems since they affect the thermal and exergetic efficiency of the cycle. Shu et al. (2014) studied 4 different working fluids with the aim to compare the performance indicators, such as power output, thermal and exergy efficiency and low investment cost. Saleh et al. (2007) presented the performance analysis of the ORC for a geothermal application with regards to 31 pure organic fluids. The selection of best working fluids with respect to different applications have been studied thoroughly and the outcomes of the investigations can be found elsewhere (Schuster et al., 2010; Gao et al., 2012; Saleh et al., 2007; Chen et al., 2010; Glover et al., 2015a; PalmaFlores et al., 2015; Shu et al., 2014).

Two classified operating conditions of the ORC waste heat recovery system can be observed: subcritical and supercritical. The operating pressure of the subcritical ORC is below the critical pressure of the working fluid; while the supercritical ORC is run at a pressure higher than the critical pressure. The investigations on supercritical ORC carried out by Glover et al. (2014), Gao et al. (2012), Shu et al. (2014) and Schuster et al. (2010) show that the heat addition to the working fluid at supercritical pressure, instead of 
subcritical pressure, can lead to a higher cycle efficiency. This is primarily due to the higher net power output and lower exergy losses. Chen et al. (2011) showed that a supercritical ORC with a zeotropic mixture as the working fluid could improve the thermal efficiency by $10 \%-30 \%$ more than the subcritical ORC.

Despite the various benefits of the supercritical ORC, high pressure in the system lead to concern about safety and availability of components. For this reason, both steady-state and dynamic simulation of the supercritical ORC-WHR system is necessary before testing the real system. The investigation of steady-state modelling of the supercritical ORC-WHR system has been presented in several reports (Chowdhury et al., 2015a and 2015b; Gao et al., 2012; Glover et al., 2015a and 2015b; Karellas et al., 2012; Schuster et al., 2010 ). However, most of these focused on the fluid selection (Gao et al., 2012; Glover et al., 2015a; Schuster et al., 2010); design, optimization and performance analysis (Schuster et al., 2010; Karellas et al., 2012; Chowdhury et al., 2015a and 2015b; Glover et al., 2015b). To the author's knowledge, the dynamic model of the supercritical ORC based waste heat recovery system using transient heat sources from an internal combustion engine has not been investigated before. In this work, the dynamic model of the evaporator and its stability and transient responses are investigated at supercritical pressure. The model is then integrated with other components of the ORC-WHR system and the performance of the completed cycle including evaporator and expander outputs are investigated. The aim of the simulation of this dynamic model is to show the effect of variable input conditions on the performance of the system and examine the output range of a typical small to a medium grade waste heat source.

The rest of the paper is organized as follows. The conceptual WHR system with a transient heat source is described in section 2. Section 3 describes the proposed model of individual components of the WHR system with a focus on the evaporator model. The performance indicators of the WHR system are discussed in section 4 Key results from the dynamic simulation of the completed cycle and a comprehensive analysis are presented in section 5. Brief conclusions of the work presented in this paper are drawn in section 6 .

\section{WASTE HEAT RECOVERY SYSTEM WITH TRANSIENT HEAT SOURCES}

The heat from an internal combustion engine is usually wasted in two ways: through the coolant, and the exhaust system. The coolant temperature fluctuates only moderately and can reach temperatures of up to $373 \mathrm{~K}$, but the engine's exhaust gases are highly transient in terms of mass flow rate and temperature and can reach

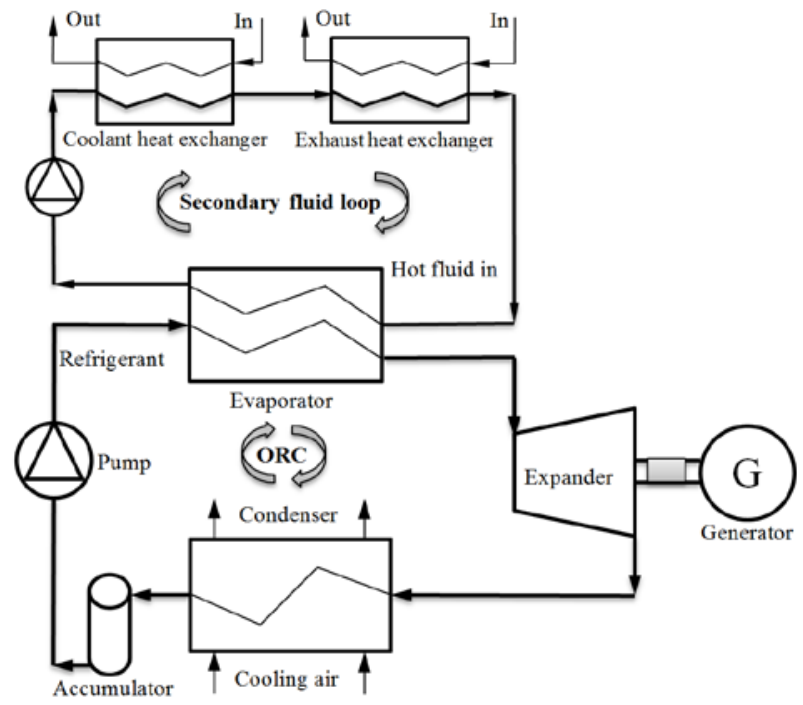

Figure 1. Conceptual two loops waste heat recovery system.

instantaneous temperatures of up to $1073 \mathrm{~K}$ (Boretti, 2012; Horst et al., 2014; Chowdhury et al., 2015b; Glover et al., 2014). When a WHR system operates with a highly transient heat source, it is challenging to keep the operating parameters within the designed ranges. Moreover, the rapid change of the upstream conditions may affect the life of the WHR components. One way to reduce the disturbance from the high-transient heat source is to divide the total heat recovery system into two parts: heat collection, and heat conversion units. This conceptual scheme is shown in Figure 1. The heat collection unit in this research is termed as the secondary fluid loop, and the heat conversion unit is termed as the ORC. In this schematic diagram, the heat from an internal combustion engine's exhaust and coolant is initially transferred to the carrier fluid, i.e. thermal oil or water, which has a high thermal inertia that prevents the fluid from changing its temperature rapidly.

The hot carrier fluid from the secondary fluid loop is then passed through the evaporator of the ORC. The liquid organic fluid is pumped to the evaporator where it is heated and vaporized by the hot carrier fluid. The vaporized fluid is then expanded and produces mechanical energy output through the shaft of the expander. A generator is normally coupled with the expander shaft to convert mechanical energy into electrical power. Exhaust vaporized fluid from the expander passes through a condenser where secondary cooling fluid, i.e. air, removes additional heat and converts the vaporized fluid back to the liquid. An accumulator is connected between the condenser and the pump to maintain sub-cooling of the organic fluid and absorbs the liquid level fluctuations of the cycle. 


\section{MODELLING OF ORGANIC RANKINE CYCLE}

\subsection{Evaporator}

The evaporator is considered as a critical part of the ORC waste heat recovery system since the heat transfer from the heat source to the working fluid takes place within this component. Several types of heat exchanger can be used as the evaporator in the WHR system, such as finned tube, shell and tube, plate, etc. The selection of heat exchanger mainly depends on the operating conditions, types and phase of fluids, flow rate and heat transfer requirements of the system (Thulukkanam, 2013). Among the conventional heat exchangers available in the market, a counter-flow plate heat exchanger (Figure 2) is chosen as the evaporator in this research because of its compactness and outstanding heat recovery qualities (Shu et al., 2014). The geometrical parameters of the selected evaporator are listed in Table 1.

Three modelling techniques for the evaporator can be found in the literature: single-segment lump method, three-zone method and distributed or finite volume (FV) method (Sun and Li, 2011). A single segment technique treats the evaporator as a single-phase (i.e. liquid) heat exchanger. The single-segment method is appropriate for modelling of evaporator when the specific heat of the fluid in the heat exchanger does not change with temperature. A zone modelling technique can be used where the evaporator has three distinct phases: liquid, liquid-vapor and superheat zone (Quoilin et al., 2010; Tian et al., 2012; Wang et al., 2012; Zhang et al., 2012 and 2014 and Hou et al., 2011). The heat transfer equations in each zone are solved by applying this method. A finite volume technique splits the evaporator into small segments and the thermo-physical properties are assumed to be constants at each segment since the temperature variations of the segment is considered low and it is reasonable to assume as a constant (Quoilin et
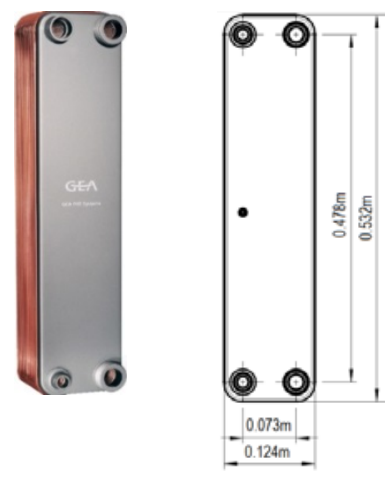

Figure 2. Plate heat exchanger (GEA Heat exchangers, 2014).
Table 1. Specification of the evaporator.

\begin{tabular}{clc}
\hline Notations & \multicolumn{1}{c}{ Parameter } & Value \\
\hline $\mathrm{A}$ & Heat transfer area of the evaporator & $5.78 \mathrm{~m}^{2}$ \\
\hline $\mathrm{L}$ & Length of each plate of the evaporator & $0.478 \mathrm{~m}$ \\
\hline $\mathrm{W}$ & Width of each plate of the evaporator & $0.124 \mathrm{~m}$ \\
\hline $\mathrm{n}$ & Number of plates & 100 \\
\hline $\mathrm{K}$ & Thermal conductivity & $0.015 \mathrm{~kW} / \mathrm{mK}$ \\
\hline
\end{tabular}

al., 2011; Sun and Li, 2011; Feru et al., 2014; Chowdhury et al., 2015a and 2015b).

When an evaporator is subjected to a supercritical pressure, thermo-physical properties of the working fluid are strongly dependent on the temperature (Karellas et al., 2012). Furthermore, a distinct phase for the fluids does not exist at supercritical conditions. For these reasons, a single segment lump method with constant fluid properties or a zone-wise technique cannot be used to calculate the heat transfer in supercritical conditions. In order to take the property changes into account, the evaporator is divided into small segments along the flow direction as shown in Figure 3, and the governing mass and energy conservation equations for each segment are solved using the finite volume method. Since the evaporator is the main contributor to the thermal inertia of the WHR system, it is necessary to develop a model that predicts the dynamic behaviour of the evaporator accurately.

The proposed dynamic model of the evaporator is built with the following assumptions:

- The model of the heat exchanger is assumed to be one-dimensional, and the heat transfer from or to the surrounding environment is negligible.

- The momentum conservation is not considered in the model and therefore, the pressure variations within the heat exchanger are neglected.

- Heat transfer from the heat source to the refrigerant or in the wall takes place through convection, not conduction.

- Heat generation within the heat exchanger is zero.

- Heat exchanger wall is uniformly built and thermophysical properties are assumed to be constant.

- Flow through the heat exchanger is uniform, and there is no viscous effect within the flow channels.

- Thermo-physical properties of refrigerant and heat

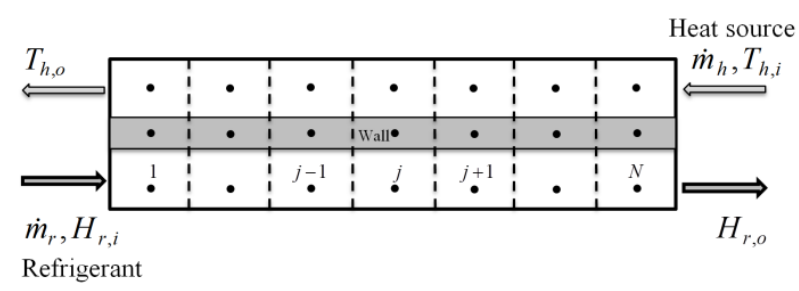

Figure 3. Finite volume discretization. 
sources for each discrete volume or segment are constant.

- Heat exchanger fouling is not included in the model.

The numerical model of the finite volume evaporator is designed with four inputs and two outputs and is shown in Figure 3. The inputs of the model are mass flow rate $\dot{m}_{r}$ and enthalpy $H_{r, i}$ of the refrigerant at the inlet of the evaporator; mass flow rate $\dot{m}_{h}$ and temperature $T_{h, i}$ of the heat source; and the outputs are the heat source outlet temperature $T_{h, o}$ and refrigerant outlet enthalpy $H_{r, o}$.

For each discrete segment, the governing mass and energy conservation equations for the refrigerant, heat exchanger wall and the heat source fluid are defined as follows:

Mass conservation of the heat source and refrigerant:

$\frac{d m_{j}}{d t}=\dot{m}_{j, \text { in }}-\dot{m}_{j, \text { out }}$

where $m_{j}$ is the mass of the fluid in each segment, which is calculated by:

$m_{j}=V_{j} \rho_{j}(t)$

where $\rho_{j}(t)$ is the density of the fluid for segment $j$ which varies with time, $V_{j}$ is the volume of each segment.

Energy conservation equation for the refrigerant:

$V_{r, j} \rho_{r, j} \frac{d H_{r, j}}{d t}+\dot{m}_{r, j}\left(H_{r, j}-H_{r, j-1}\right)-Q_{r, j}=0$

Energy conservation equation for the heat source fluid:

$V_{h, j} \rho_{h, j} c_{p_{h, j}} \frac{d T_{h, j}}{d t}+\dot{m}_{h, j} c_{p_{h, j}}\left(T_{h, j}-T_{h, j+1}\right)+Q_{h, j}=0$

Energy conservation equation for the heat exchanger wall:

$m_{\text {wall }, j} C_{p_{\text {wall }, j}} \frac{d T_{\text {wall }, j}}{d t}-Q_{h, j}+Q_{r, j}=0$

where $Q_{j}$ is the evaporator heat input at segment $j$ and is defined by

$Q_{r, j}=A_{r, j} h_{r, j}\left(T_{\text {wall }, j}-T_{r, j}\right)$
$Q_{h, j}=A_{h, j} h_{h, j}\left(T_{h, j}-T_{\text {wall }, j}\right)$

The heat transfer area, volume and mass of the heat exchanger for each segment are calculated as follows:

$$
\begin{aligned}
& A_{j}=\frac{A}{N} \\
& V_{j}=\frac{V}{N} \\
& m_{\text {wall }, j}=\frac{m_{\text {wall }}}{N}
\end{aligned}
$$

where $A, V$ and $m_{\text {wall }}$ are the total heat transfer area $\left(\mathrm{m}^{2}\right)$, empty volume $\left(\mathrm{m}^{3}\right)$ and empty weight $(\mathrm{kg})$ of the heat exchanger, respectively; $N$ is the number of segments; $h_{h, j}$ and $h_{r, j}$ are the convective heat transfer coefficients $\left(\mathrm{kW} / \mathrm{m}^{2} \mathrm{~K}\right)$ of the heat source fluid and refrigerant with the wall; $\dot{m}_{h, j}(\mathrm{~kg} / \mathrm{s})$ and $\dot{m}_{r, j}(\mathrm{~kg} / \mathrm{s})$ are the mass flow rate of heat source and refrigerant respectively; $c_{p_{h, j}}$ and $c_{p_{\text {wall }}, j}(\mathrm{~kJ} / \mathrm{kg} . \mathrm{K})$ are the specific heat capacity of the heat source and heat exchanger wall, respectively; $H_{r, j}$ is the specific enthalpy of the refrigerant in $\mathrm{kJ} / \mathrm{kg}$.

In this method, the outlet conditions of the heat source and refrigerant are initially guessed. With the inlet and initial outlet conditions, the simultaneous differential equations for the heat source, refrigerant, and the wall are solved accordingly. The solution starts from the $1^{\text {st }}$ segment and finishes at the $N^{\text {th }}$ segment as shown in Figure 3.

The convective heat transfer coefficients in Equations (6-7) for each segment are calculated based on the local temperature and thermo-physical properties of the fluids. The thermo-physical properties of the fluids in supercritical pressures are highly variable with temperature. For example, the variation of specific heat capacity, Prandtl number, viscosity and thermal conductivity of R134a at different supercritical pressures, with temperature are shown in Figures 4-5. These properties are obtained from the U.S. National Institute of Standards and Technology (NIST) database called REFPROP (Lemmon et al., 2010). It can be seen from the figures that sudden variations occur mostly around pseudo-critical temperature and the effects become lesser at higher pressures. However, the variation effects cannot be avoided completely at the higher pressure. Since the heat transfer coefficients of the fluids are calculated with these properties, they have a strong influence in the heat transfer calculation. For this reason, instead of using classical correlation, the 
Chowdhury et al.

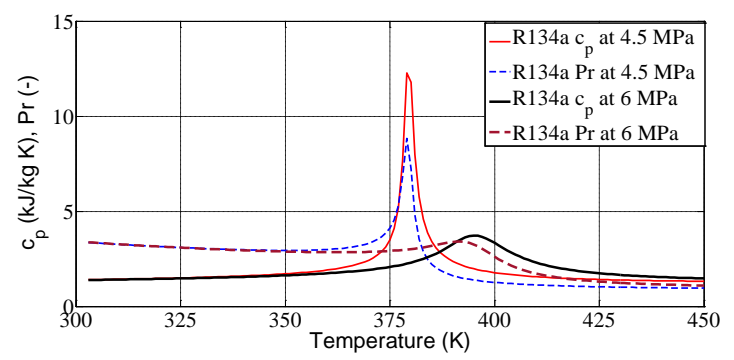

Figure 4. Variation of specific heat capacity and Prandtl number with temperature.

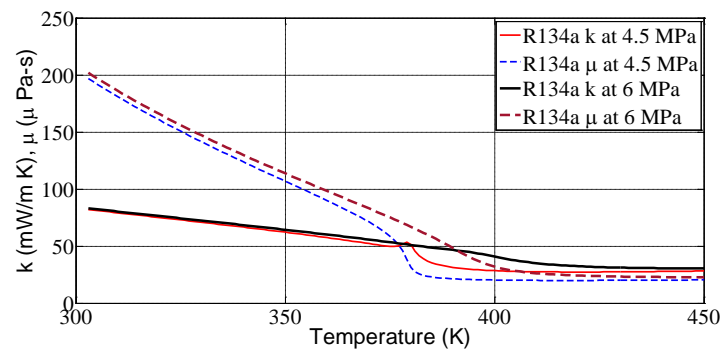

Figure 5. Variation of thermal conductivity and dynamic viscosity with temperature.

Jackson correlation for supercritical fluids (Jackson and Hall, 1979a and 1979b) is used to calculate the Nusselt number $\mathrm{Nu}$ for the refrigerant in Equation (11). This correlation neutralizes the variation effects around the pseudo-critical point.

The Nusselt number correlation for the refrigerant is calculated as follows:

$N u_{r}=0.0183 \operatorname{Re}_{b}{ }^{0.82} \operatorname{Pr}^{0.5}\left(\frac{\rho_{\text {wall }}}{\rho_{b}}\right)^{0.3}\left(\frac{\bar{c}_{p}}{c_{p_{b}}}\right)^{n}$

where $\bar{c}_{p}=\frac{H_{\text {wall }}-H_{b}}{T_{\text {wall }}-T_{b}}$

$n=0.4$ for $T_{b}<T_{\text {wall }}<T_{p c}$ and $1.2 T_{p c}<T_{b}<T_{\text {wall }}$

$n=0.4+0.2\left(\frac{T_{\text {wall }}}{T_{p c}}-1\right)$ for $T_{b}<T_{p c}<T_{\text {wall }}$

$n=0.4+0.2\left(\frac{T_{\text {wall }}}{T_{p c}}-1\right)\left(1-5\left(\frac{T_{b}}{T_{p c}}-1\right)\right)$

for $T_{p c}<T_{b}<1.2 T_{p c}$ and $T_{b}<T_{\text {wall }}$

where $T_{b}$ is the bulk temperature of the refrigerant, $T_{p c}$ is the pseudo-critical temperature of the refrigerant; $\bar{c}_{p}$ is the average specific heat capacity of the medium; $\rho_{\text {wall }}$ is the density of the working fluid at wall temperature and $\rho_{b}$ is the density of the working fluid at bulk temperature; $H_{\text {wall }}$ and $H_{b}$ are the enthalpy of the working fluid at wall and bulk temperature, respectively. In this case, the bulk temperature is the same as the average refrigerant temperature of the cell.

The heat transfer coefficient for the heat source is calculated with Equation (14) using the Dittus Boelter correlation as suggested by Sharabi et al. (2008).

$$
N u_{h}=0.023 \operatorname{Re}^{0.8} \operatorname{Pr}^{0.3}
$$

The convective heat transfer coefficients of the fluids are calculated by Equation (15), whereas the Reynolds number $\mathrm{Re}$ is calculated using Equation (16).

$$
\begin{aligned}
N u & =\frac{h D_{h}}{K} \\
\operatorname{Re} & =\frac{\rho V D_{h}}{\mu}
\end{aligned}
$$

where $D_{h}$ is the hydraulic diameter of the plate heat exchanger ( $m$ ), $\rho$ is the density ( $\mathrm{kg} / \mathrm{m}^{3}$ ) of the fluid, $\mu$ is the dynamic viscosity ( Pa.s ) and $V$ is the velocity of the fluid $(\mathrm{m} / \mathrm{s})$.

\subsubsection{Performance of evaporator model}

The working fluid and heat source used in this simulation are R134a refrigerant and hot water, respectively. The performances of the evaporator model were tested at a supercritical pressure of $6 \mathrm{MPa}$. This value is far away from the critical pressure of the R134a refrigerant, which is $4.06 \mathrm{MPa}$. As reported by Karellas et al. (2012), when the pressure of the evaporator rises, the error of the finite volume calculation is reduced, and the procedure converges with fewer segments. The

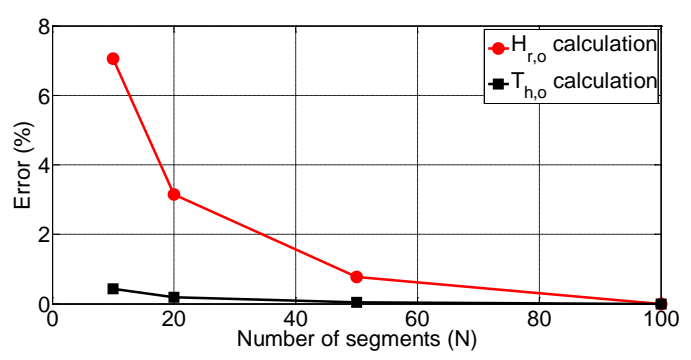

Figure 6. Calculation error of dynamic evaporator model for different segment numbers. 
prediction errors of the refrigerant enthalpy and the heat source temperature are calculated for the different numbers of segments against the reference 100 segments model and shown in Figure 6. The errors in the prediction of the refrigerant enthalpy for 10, 20 and 50 segments model are $7.05 \%, 3.14 \%$, and $0.77 \%$, respectively (Figure 6). On the other hand, the errors in the prediction of the heat source outlet temperature are found to be less than $1 \%$ in all the cases. The number of segments for the evaporator is set to 20 in this simulation, as it is a good compromise between iteration time and the accuracy of the model.

All thermo-physical properties of the heat source fluid and R134a are obtained from the REFPROP database. This database is used to calculate the thermodynamic properties of pure fluids and predefined mixtures.

This section presents the performance analysis of the dynamic evaporator model as follows.

\subsubsection{Stability analysis}

The stability of the developed transient model of the evaporator was carried out under different inlet and outlet conditions. During the first iteration, two nominal outputs for the heat source temperature and refrigerant enthalpy are assumed with initial values. These two outlet conditions are then used to calculate the initial temperature and enthalpy for each segment of the evaporator. The initial wall temperature of each cell is calculated as follows:

$T_{\text {wall }, j}=\frac{T_{h, j}+T_{r, j}}{2}$

The initial thermo-physical properties of the fluids in each cell are obtained from their corresponding temperatures and pressures. The initial conditions for the second iteration are updated from the output of the first iteration. Three different sets of initial outlet conditions: Equal, Reasonable and Very low-Very high

Table 2. Initial assumptions and convergence status for stability analysis of the evaporator model.

\begin{tabular}{|c|c|c|c|c|}
\hline Guesses & $\begin{array}{c}\text { Inlet conditions } \\
T(K) \\
H(k J / k g)\end{array}$ & $\begin{array}{c}\text { Initial guess for } \\
\text { outlet variables } \\
T(K) \\
H(k J / k g)\end{array}$ & $\begin{array}{c}\text { Actual outputs } \\
T(K) \\
H(k J / k g)\end{array}$ & $\begin{array}{l}\text { Convergence } \\
\text { status }\end{array}$ \\
\hline \multirow{2}{*}{ Equal } & $T_{h, i}=507$ & $T_{h, o}=507$ & 483 & \multirow{2}{*}{ Converged } \\
\hline & $H_{r, i}=242.09$ & $H_{r, o}=242.09$ & 407.7 & \\
\hline \multirow{2}{*}{ Reasonable } & $T_{h, i}=507$ & $T_{h, o}=480.83$ & 483 & \multirow{2}{*}{ Converged } \\
\hline & $H_{r, i}=242.09$ & $H_{r, o}=407.45$ & 407.7 & \\
\hline \multirow{2}{*}{$\begin{array}{l}\text { Very low } \\
\text { Very high }\end{array}$} & $T_{h, i}=507$ & $T_{h, o}=298.22$ & 483 & \multirow{2}{*}{ Converged } \\
\hline & $H_{r, i}=242.09$ & $H_{r, o}=647.8$ & 407.7 & \\
\hline
\end{tabular}

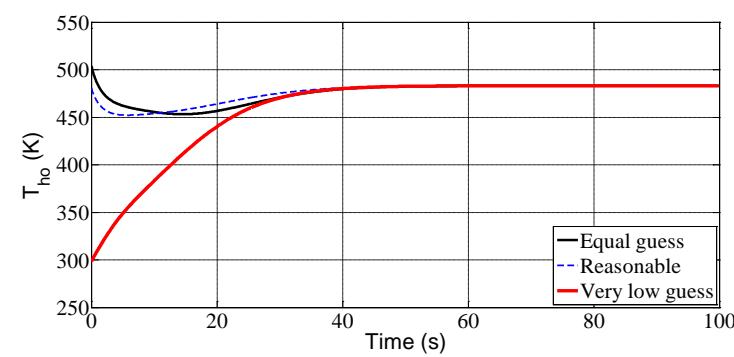

Figure 7. Steady state convergence of heat source outlet temperature.

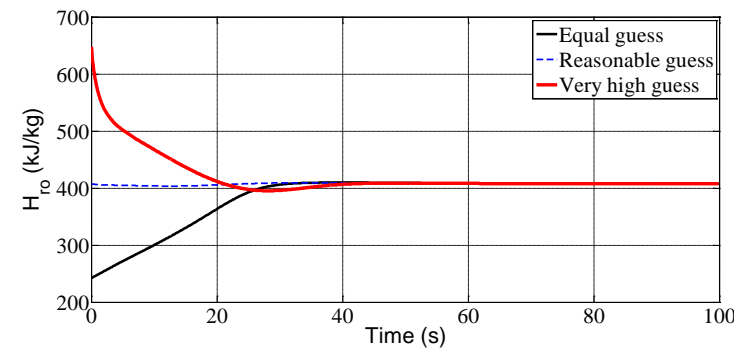

Figure 8. Steady state convergence of refrigerant outlet enthalpy.

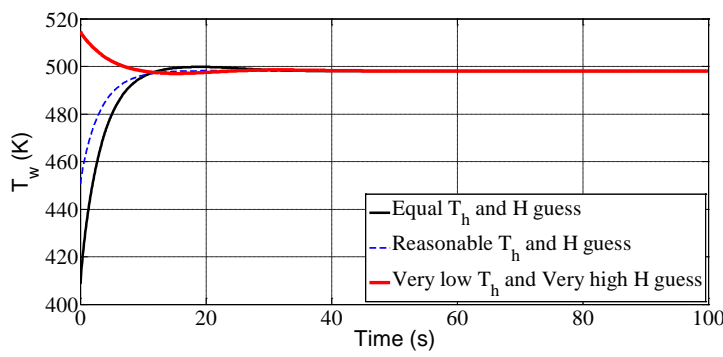

Figure 9. Steady state convergence of wall temperature.

are assumed at the first iteration. The values and their convergence status are shown in Table 2 and Figures 79. During the simulation, all inlet variables of the evaporator model were kept constant so that the model could be converged to steady state condition without having any transient disturbance.

Results from the stability analysis show that the model converged to the same steady state value with three different initial guesses. This means that the model is robust and still converged to steady state with any initial values.

\subsubsection{Transient responses}

In this section, the transient behaviour of the evaporator is investigated in two scenarios: step changes in inlet temperature and mass flow rate of the heat source. The number of finite volumes, the pressure of the evaporator, 
the geometry, and the fluids have all remained the same, as for the stability analysis.

Figures 10-12 show the outputs of the evaporator model with respect to the step change $(-48 \mathrm{~K})$ to the heat source inlet temperature at $t=150$ seconds. Prior to the step change, the model was allowed to converge into a steady-state value to eliminate the effect of initial assumptions. During the transient response simulation, all other inlet variables were kept constant.

Similar to the step change of the heat source inlet temperature, a step change $(-0.2 \mathrm{~kg} / \mathrm{s})$ of the heat source mass flow rate is introduced at $t=150$ seconds. The responses of this step change are shown in Figures 1315. The responses and convergences of the outlet variables with regards to the step changes in the temperature and mass flow rate demonstrate that the

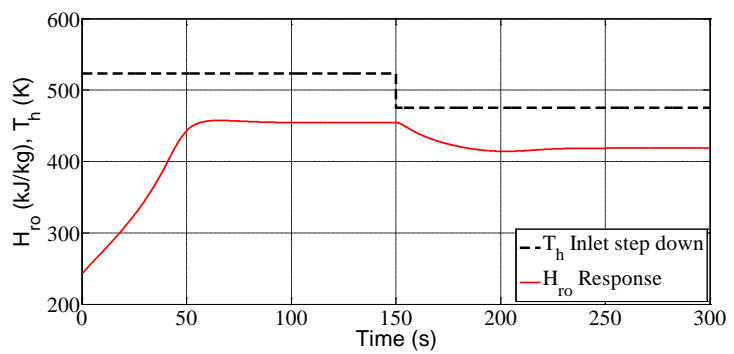

Figure 10. Response of refrigerant outlet enthalpy with respect to an inlet step of heat source temperature.

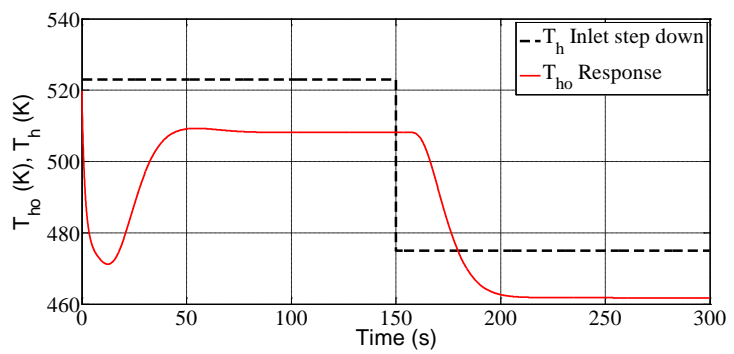

Figure 11. Response of heat source outlet temperature with respect to an inlet step of heat source temperature.

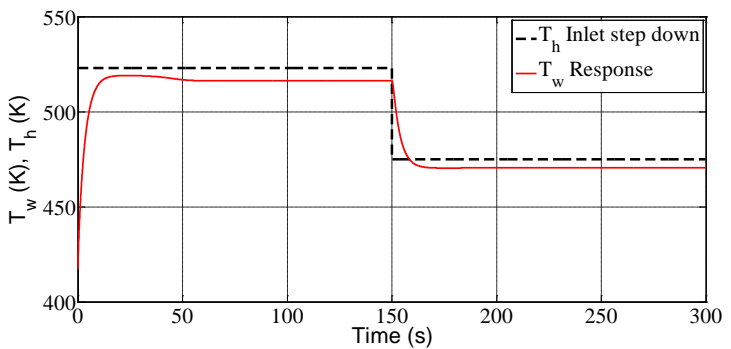

Figure 12. Response of wall temperature with respect to an inlet step of heat source temperature.

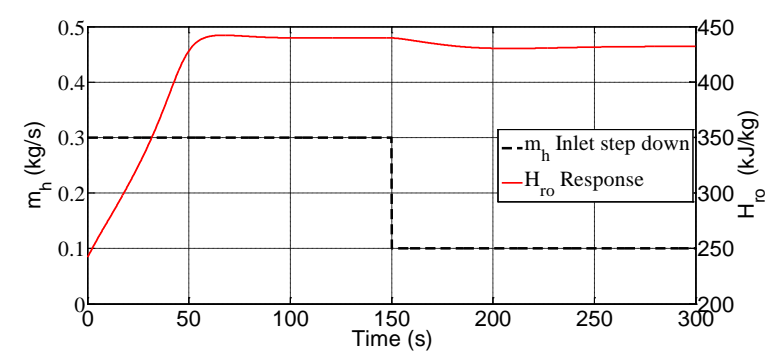

Figure 13. Response of refrigerant outlet enthalpy with respect to an inlet step of heat source mass flow rate.

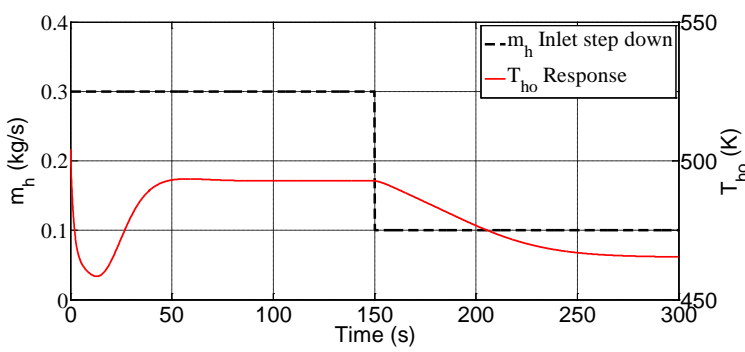

Figure 14. Response of heat source outlet temperature with respect to an inlet step of heat source mass flow rate.

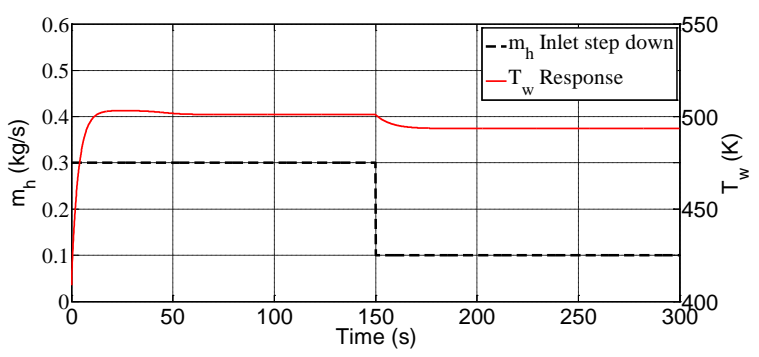

Figure 15. Response of wall temperature with respect to an inlet step of heat source mass flow rate.

model is robustly built to take into account the transient behaviour of the inlet conditions.

\subsection{Pump}

In this research, a volumetric diaphragm pump (HydraCell Industrial pumps, 2015) is used in the simulation. The selected pump has a maximum outlet and inlet pressure of $7 \mathrm{MPa}$ and $1.7 \mathrm{MPa}$, respectively. The highest speed of the pump can be up to 1750 RPM. The maximum delivery capacity of the pump at this speed is 11.3 litres/min. The relationship between mass flow rate and the pump speed can be derived from the performance curve of the selected pump and is expressed as follows (Zhang et al., 2014): 
$\frac{\dot{m}_{p 1}}{\dot{m}_{p 2}}=\frac{N_{p 1}}{N_{p 1}}$

where $\dot{m}_{p}$ is the mass flow rate of the pump in $\mathrm{kg} / \mathrm{s}$ and $N_{p}$ is the corresponding pump speed (RPM).

For a given specific volume, $\bar{v}_{p}\left(\mathrm{~m}^{3} / \mathrm{kg}\right)$ and isentropic efficiency of the pump $\eta_{p}$, the outlet enthalpy and pump work can be obtained from the following equations:

$H_{p o}=\frac{\bar{v}_{p}\left(P_{p o}-P_{p i}\right)}{\eta_{p}}+H_{p i}$

$W_{p}=\frac{\bar{v}_{p}\left(P_{p o}-P_{p i}\right) \dot{m}_{p}}{\eta_{p}}$

where $H_{p i}$ and $H_{p o}$ are the enthalpy of the fluid at the inlet and outlet of the pump, respectively. $P_{p i}$ is the pump inlet pressure and $P_{p o}$ is the pump outlet pressure. The isentropic efficiency of the pump $\eta_{p}$ is assumed to be constant and equal to 0.75 in this simulation (Glover et al., 2015b; Boretti, 2012).

\subsection{Expander}

An expander is a mechanical device which extracts heat energy and converts it into mechanical rotational energy. Several types of expander are used in smaller scale ORC units, including reciprocating, screw, turbine and scroll. In this research, a zero-dimensional thermodynamic model of a turbine is used for the simulation of the expander. The thermodynamic model of the expander is developed based on the steady state condition since the response time of the turbomachinery compared to the evaporator is very small and can normally be neglected (Quoilin et al., 2011; Bamgbopa and Uzgoren, 2013).

The isentropic expansion of the expander is calculated by equation (21).

$W_{\text {isen }}=\left(H_{\text {exp }, i}-H_{\text {exp }, o}\right)$

where $w_{\text {isen }}$ is the isentropic expansion work, $H_{\text {exp }, i}$ is the enthalpy at the expander inlet, and $H_{\text {exp }, o}$ is the enthalpy at the expander outlet.

The total work output of the expander is obtained by multiplying the mass flow rate with the specific work output as follows:

$W_{\text {exp }}=\dot{m}_{\text {exp }} \eta_{\text {exp }} W_{\text {isen }}$ where $\eta_{\exp }$ is the isentropic efficiency of the expander, which is assumed to be 0.85 in this research. This value is within the common range as prescribed in (Glover et al., 2015b; Gao et al., 2012; Boretti, 2012).

\subsection{Condenser and accumulator}

The condenser is a heat transfer device that removes heat from the vaporized refrigerant and returns it back to its liquid form. The condenser in the dynamic WHR system is considered to be a steady state device. In Quoilin et al. (2011), a dynamic model of the condenser was avoided in order to reduce the computational time. In this research, a thermodynamic model of the condenser based on the state enthalpy is represented by the following equation:

$$
Q_{c o n}=\dot{m}_{c o n}\left(H_{\text {exp }, o}-H_{a c, i}\right)
$$

where $Q_{\text {con }}$ is the condenser cooling power $(k W), \dot{m}_{\text {con }}$ is the mass flow rate of refrigerant through the condenser which is the same as the mass flow of refrigerant at the pump. $H_{a c, i}$ is the enthalpy at the inlet of the accumulator.

In this simulation, it is assumed that sufficient cooling air is supplied to the condenser so that the liquid vapour refrigerant from the expander is cooled down to the initial inlet temperature of the pump.

The accumulator is a liquid storage tank that is fitted in between the condenser and the pump, which absorbs the fluctuation of the fluid level in the cycle. It is assumed that the accumulator is large enough that it can maintain the sub-cooled state of the refrigerant even if the inlet condition of the accumulator is changed. Under this assumption, the accumulator can be treated as a steady state device, and the enthalpy at the outlet of the accumulator is equal to the enthalpy at the inlet of the pump, i.e.

$H_{a c, o}=H_{p, i}$

where $H_{a c, o}$ is the enthalpy at the accumulator outlet and $H_{p, i}$ is the enthalpy at the pump inlet.

\subsection{Overall model of waste heat recovery system}

The overall model of the cycle shown in Figure 16 is built by interconnecting all subcomponents in the WHR system. The inputs and outputs of the adjacent components are as follows:

- The pressure at the pump outlet is equal to the pressure of the evaporator and at the expander inlet, 


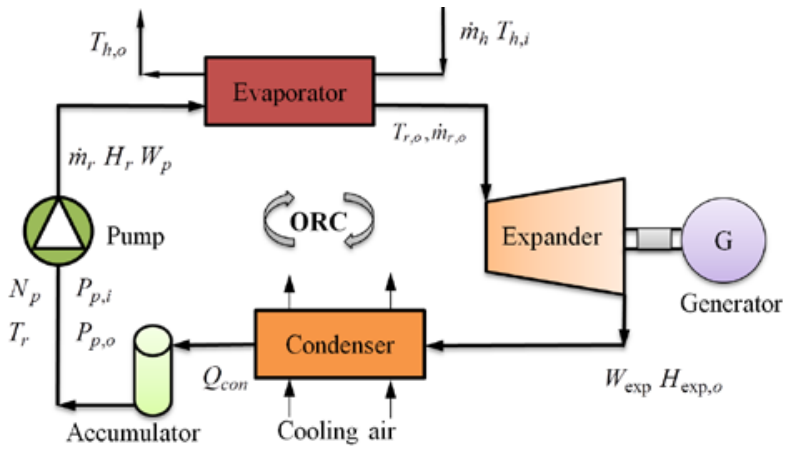

Figure 16. Overall model of the ORC-WHR system.

such that $P_{p, o}=P_{e v, i}=P_{e v, o}=P_{\text {exp }, i}$.

- The pressure at the expander outlet and in the condenser is equal to the pressure at the pump inlet, such that $P_{\text {exp }, o}=P_{c o n}=P_{p, i}$.

- The enthalpy at the pump outlet and the evaporator inlet are equal, $H_{p, o}=H_{r, i}$.

- The enthalpy and specific volume of the refrigerant at the pump inlet is a function of the inlet pressure, $H_{p, i}, \bar{v}_{p}=f\left(P_{p, i}\right)$

- The temperature of the refrigerant at the inlet of the evaporator is a function of the enthalpy and pressure at the pump outlet, $T_{r, i}=f\left(P_{p, o}, H_{p, o}\right)$.

- The enthalpy at the evaporator outlet and the expander inlet are equal, $H_{r, o}=H_{\text {exp }, i}$.

- The enthalpy at the condenser outlet and the pump inlet through the accumulator are equal, $H_{c o n, o}=H_{p, i}$.

By interconnecting the individual inputs and outputs of each component, a set of overall model inputsoutputs can be defined and are listed in Table 3.

\section{PERFORMANCE EVALUATION OF WASTE HEAT RECOVERY SYSTEM}

The performance of the ORC-WHR system is described by two basic parameters: cycle efficiency and heat recovery efficiency as follows.

$\eta_{c y}=\frac{W_{\text {Net }}}{Q_{e v}}$

$\eta_{h r}=\frac{Q_{e v}}{Q_{h}}$

where $\eta_{c y}$ is the cycle efficiency, which is the ratio of net work output to the heat recovered at the evaporator, $\eta_{h r}$ is the heat recovery efficiency which is defined as
Table 3. Overall model parameters.

\begin{tabular}{cc}
\hline Input variables & Output variables \\
\hline$N_{p}, P_{p, i}, P_{p, o}, \dot{m}_{h}, T_{h}, T_{r}$ & $Q_{e v}, T_{r, o}, T_{h, o}, W_{p}, W_{\exp }, Q_{c o n}$ \\
\hline
\end{tabular}

the amount of heat recovered from the given heat source. $Q_{e v}$ and $Q_{h}$ are the evaporator heat input and available heat in the heat source, respectively.

The net work output $W_{\text {net }}$ in equation (25) is calculated by subtracting the pump work from the expander gross work as follows:

$W_{\text {net }}=\left(W_{\text {exp }}-W_{p}\right)$

The available heat $Q_{h}$ is calculated by

$Q_{h}=\dot{m}_{h}\left(H_{h, i}-H_{h, \text { ref }}\right)$

where $H_{h, i}$ and $H_{h, \text { ref }}$ are the heat source enthalpy at the inlet of the evaporator and at the reference temperature $303 \mathrm{~K}$, respectively.

\section{SIMULATION OF DYNAMIC WASTE HEAT RECOVERY SYSTEM}

A random heat source in terms of mass flow rate and temperature (Figure 17) is generated for the investigation of the waste heat recovery process at supercritical conditions. This heat source is from the carrier fluid, representing the total heat that is collected from the internal combustion engine's exhaust and coolant, via a secondary heat transfer fluid loop as illustrated in Figure 1. The working fluid of the ORC used in this simulation is R134a, which is readily available, widely used for commercial purposes and has a high auto-ignition temperature. To investigate the effect of operating parameters on the system output, a random pump speed profile ranging from 200 RPM to 1750 RPM, and its corresponding mass flow rate shown

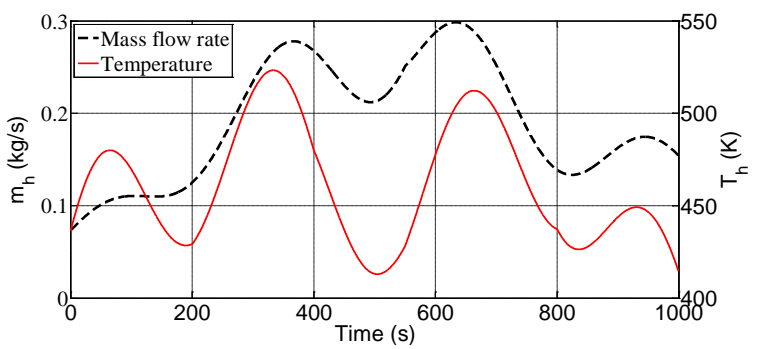

Figure 17. Heat source mass flow rate and temperature with time. 


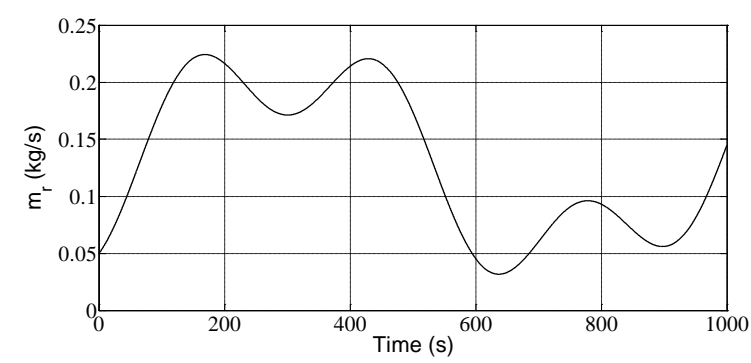

Figure 18. Mass flow rate of refrigerant with time.

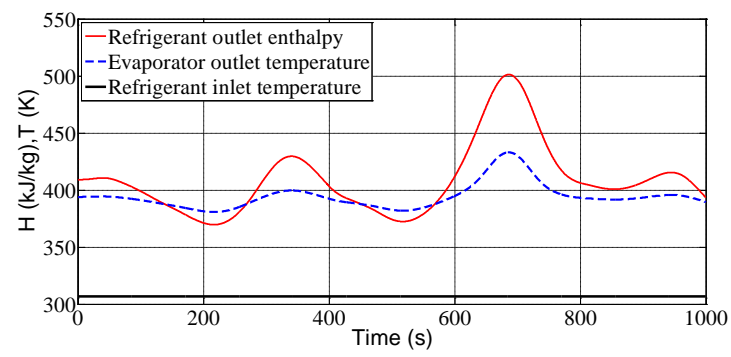

Figure 19. Variation of enthalpy and refrigerant temperature with time.

in Figure 18 is used in the simulation. The minimum and maximum pump speed are set according to the pump specifications as discussed in section 3 . The range of the mass flow rate profile of the selected pump is $0.03 \mathrm{~kg} / \mathrm{s}$ to $0.22 \mathrm{~kg} / \mathrm{s}$. The pump outlet pressure is set to $6 \mathrm{MPa}$, which is well above the critical pressure of the R134a refrigerant. The inlet pressure of the pump is set to $0.77 \mathrm{MPa}$ which is the minimum pressure at the nominal condenser temperature of $303 \mathrm{~K}$ (Glover et al., 2015a). Both the inlet and the outlet pressure are assumed to be constant since the momentum conservation of the evaporator model is neglected as discussed in section 3 .

The number of finite volume segments of the evaporator for the dynamic simulation is set to 20 and it is expected that a higher number of segments could increase the accuracy of the evaporator model. However, a higher number of segments would also increase the computation time. The time step of the numerical model depends on the geometry of the evaporator, the number of finite volume segments, the density of the fluids in each segment and the mass flow rate of the fluids. The minimum time step of the evaporator model is calculated using Equation (29).

$\Delta t=\min \left[\frac{\rho_{r, j}^{t} \times V_{r, j}}{\dot{m}_{r, j}^{t}}, \frac{\rho_{h, j}^{t} \times V_{h, j}}{\dot{m}_{h, j}^{t}}\right]$

where $V$ is the volume of each segment in $m^{3}$.
Figure 19 shows the variation of the refrigerant's enthalpy and temperature at the outlet of the evaporator with time. A maximum instantaneous enthalpy of 501 $\mathrm{kJ} / \mathrm{kg}$ can be observed. The maximum and minimum temperature at the evaporator outlet was found to be 433 $\mathrm{K}$ and $380 \mathrm{~K}$ against a constant inlet temperature of 307 $\mathrm{K}$. This output temperature range is lower than the upper limit of the evaporation temperature for R134a, which is limited by its thermal decomposition temperature of $523 \mathrm{~K}$. The calculated evaporator outlet temperature is a function of the enthalpy and pressure, which is obtained from the REFPROP. However, the variation of the evaporator temperature is primarily dependent on the combination of heat source inputs and the refrigerant mass flow rate. In the WHR system, the heat source conditions are normally not known in advance. The variation of evaporator outlet temperature is therefore controlled by regulating the refrigerant flow to the evaporator. Due to the thermal inertia of the evaporator, a delayed response of the evaporator temperature against the refrigerant flow can be observed in Figures 18-19.

Figure 20 shows the variation of the heat source outlet temperature with time. A minimum outlet temperature of $387 \mathrm{~K}$ from the selected heat source is observed. The lower the temperature at the outlet of the evaporator, the higher the heat recovery that can be achieved. The factors influence the heat source outlet temperatures are the mass flow rate and temperature of the refrigerant at the inlet of the evaporator. Since the refrigerant temperature at the evaporator inlet is

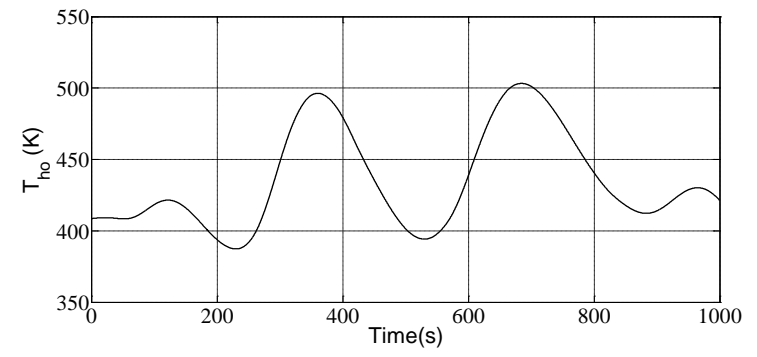

Figure 20. Heat source outlet temperature with time.

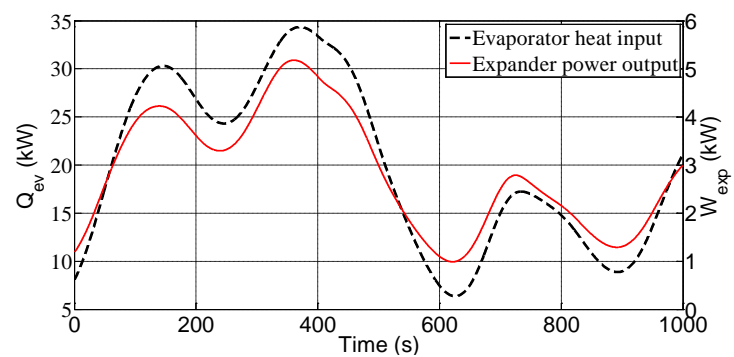

Figure 21. Evaporator heat input and expander power output with time. 
considered to be constant, the mass flow rate of the refrigerant is primarily responsible for determining the heat source outlet conditions.

The evaporator heat input to the ORC-WHR system is shown in Figure 21. It demonstrates that the minimum and maximum heat absorbed by the evaporator is 6.38 $\mathrm{kW}$ and $34.34 \mathrm{~kW}$, respectively. The amount of heat absorbed is dependent on the combination of the heat source and refrigerant flow at each time step. In the simulation, the maximum heat absorption is observed when the waste heat flows through the evaporator at $0.277 \mathrm{~kg} / \mathrm{s}$ with the temperature of $507.5 \mathrm{~K}$ and the refrigerant flows at $0.2 \mathrm{~kg} / \mathrm{s}$. In Figure 21, the expander output profile is similar to the evaporator heat input profile. This is as expected because the enthalpy at the outlet of the evaporator is assumed to be equal to the enthalpy at the inlet of the expander. A maximum power output of $5.19 \mathrm{~kW}$ is observed in this simulation. It can be seen from the figure that at certain times, especially after 600 seconds, the ratio of the expander power output over the amount of heat input in the evaporator is high. This is because of the higher enthalpy at the evaporator outlet (Figure 19), which gives a higher enthalpy difference at the expander, and as a result, a higher output for the system.

The cycle efficiency of the ORC depends on several factors including the temperature of the evaporator, the heat of vaporization, the pressure ratio at the expander, etc. Figure 22 shows the cycle efficiency of the dynamic ORC-WHR model with respect to the selected heat source. The cycle efficiency varies from $8.7 \%$ to $14.43 \%$; these figures may change depending on the

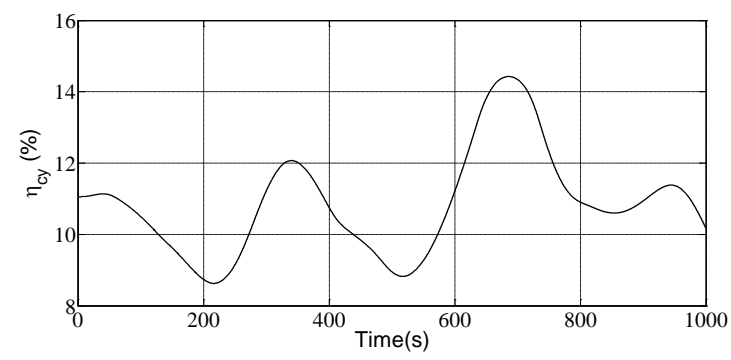

Figure 22. ORC cycle efficiency.

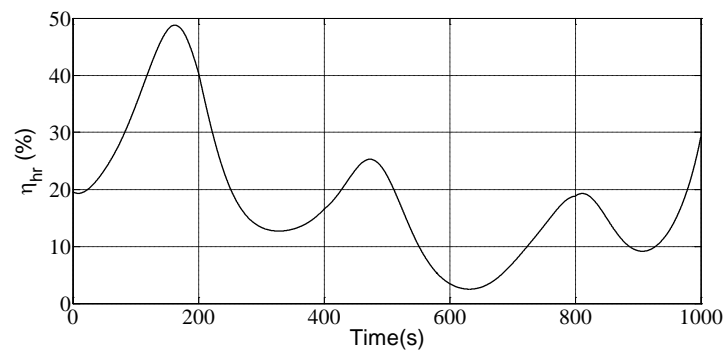

Figure 23. ORC-waste heat recovery efficiency. combination of the mass flow rate and temperature of the heat source and refrigerant. The WHR system in this simulation can recover up to $48.8 \%$ (Figure 23 ) of the heat from the variable heat source shown in Figure 17. A better-designed heat exchanger should be able to recover more heat from the waste heat sources. It can be seen from Figures 22 and 23 that the trends of the cycle and heat recovery efficiency are opposite to each other. The benefit of the supercritical conditions is that a higher thermal efficiency can be obtained at the expense of a lower heat recovery. In order to achieve higher cycle efficiency, the evaporator outlet temperature should be maintained as high as possible. For a given heat source, the higher evaporator temperature can be obtained if a lower rate of refrigerant flow is maintained in the evaporator. However, this makes the heat recovery of the system lower. An optimization of these two efficiencies can derive the most beneficial operating condition of the WHR system.

\section{CONCLUSION}

The dynamic model of the supercritical ORC based waste heat recovery system has been presented in this paper. The evaporator, the key contributor to the thermal inertia, has been modelled with the finite volume technique. The stability and transient responses of the model have been thoroughly investigated. The integration of the evaporator model with other components of the ORC-WHR system has also been presented. The performance of the WHR system including cycle and heat recovery efficiency with the transient heat source has been investigated. The developed model is able to depict the ORC-WHR system with a transient scenario at supercritical pressure. It also shows the effect of the mass flow rate of the refrigerant on the evaporator outlet temperature, which is the critical parameter for the control of the WHR system in real time.

The concept of two loops, ORC and secondary, waste heat recovery system for internal combustion engines has potential to reduce the highly transient heat input in the ORC-WHR systems used in automobile applications.

ACKNOWLEDGEMENT- This work is a part of the Ph.D. project supported by the Queen's Special Research Scholarship, School of Mechanical and Aerospace Engineering, Queen's University Belfast, UK. The sponsorship is gratefully acknowledged. 


\section{REFERENCES}

Bamgbopa, M. O. and Uzgoren, E. (2013). Numerical analysis of an organic Rankine cycle under steady and variable heat input. Applied Energy 107, 219-228.

Boretti, A. (2012). Recovery of exhaust and coolant heat with R245fa organic Rankine cycles in a hybrid passenger car with a naturally aspirated gasoline engine. Applied Thermal Engineering 36, 73-77.

Chen, C., Chang, F., Chao, T., Chen, H. and Lee, J. (2014). Heat-Exchanger Network Synthesis Involving Organic Rankine Cycle for Waste Heat Recovery. Industrial \& Engineering Chemistry Research 53, 16924-16936.

Chen, H., Goswami, D.Y., Rahman, M.M. and Stefanakos, E.K. (2011). A supercritical Rankine cycle using zeotropic mixture working fluids for the conversion of low-grade heat into power. Energy 36, 549-555.

Chen, H., Goswami, D.Y. and Stefanakos, E.K. (2010). A review of thermodynamic cycles and working fluids for the conversion of low-grade heat. Renewable and Sustainable Energy Reviews 14, 3059-3067.

Chowdhury, J.I., Nguyen, B.K. and Thornhill, D. (2015a). Modelling of Evaporator in Waste Heat Recovery System using Finite Volume Method and Fuzzy Technique. Energies 8, 14078-14097.

Chowdhury, J.I., Nguyen, B.K. and Thornhill, D., (2015b). Modelling of organic Rankine cycle for waste heat recovery process in supercritical condition. Int. $J$ Mechanical, Aerospace, Industrial, Mechatronic and Manufacturing Engineering 9, 453-458.

Feru, E., Willems, F., Jager, B.d. and Steinbuch, M. (2014). Modeling and control of a parallel waste heat recovery system for Euro-VI heavy-duty diesel engines. Energies 7, 6571-6592.

Gao, H., Liu, C., He, C., Xu, X., Wu, S. and Li, Y. (2012). Performance Analysis and Working Fluid Selection of a Supercritical Organic Rankine Cycle for Low Grade Waste Heat Recovery. Energies 5, 32333247.

GEA Heat Exchangers (2014). GEA Heat Exchangers, Inc. http://www.gea-phe.com/usa.

Glover, S., Douglas, R., Glover, L., McCullough, G. and McKenna, S. (2015a). Automotive Waste Heat
Recovery: Working Fluid Selection and Related Boundary Conditions. Int. J. Automotive Technology 16, 399-409.

Glover, S., Douglas, R., De Rosa, M., Zhang, X. and Glover, L., (2015b). Simulation of a multiple heat source supercritical ORC (Organic Rankine Cycle) for vehicle waste heat recovery. Energy 93, 2, 1568-1580.

Glover, S., Douglas, R., Glover, L. and McCullough, G. (2014). Preliminary analysis of organic Rankine cycles to improve vehicle efficiency. Proceedings of the Institution of Mechanical Engineers - Part D - Journal of Automobile Engineering 228, 10, 1142-1153.

Hou, G., Sun, R., Hu, G. and Zhang, J. (2011). Supervisory predictive control of evaporator in Organic Rankine Cycle (ORC) system for waste heat recovery. Int. Conf. Advanced Mechatronic Systems 1, 306-311.

Horst, T.A., Tegethoff, W., Eilts, P. and Koehler, J. (2014). Prediction of dynamic Rankine Cycle waste heat recovery performance and fuel saving potential in passenger car applications considering interactions with vehicles' energy management. Energy Conversion and Management 78, 438-451.

Hydra-Cell Industrial pumps (2015): Installation and service manual. Wanner Engineering, Inc. http://www.hydra-cell.com/product/D03-hydracellpump.html.

Imran, M., Park, B., Kim, H., Lee, D. and Usman, M. (2015).Economic assessment of greenhouse gas reduction through low-grade waste heat recovery using organic Rankine cycle(ORC). J. Mechanical Science and Technology 29, 835-843.

International energy statistics (2016). U.S. Energy information administration (EIA). http://www.eia.gov/cfapps/ipdbproject/IEDIndex3.cfm? tid=44\&pid=44\&aid $=2$

Jackson, J. D. and Hall, W. B. (1979a). Forced convection heat transfer to fluids at supercritical pressure. Turbulent Forced Convection in Channels and Bundles, S. Kakac and D. B. Spalding, Eds. Hemisphere, USA.

Jackson, J. D. and Hall, W. B. (1979b). Influences of buoyancy on heat transfer to fluids flowing in vertical tubes under turbulent conditions. Turbulent Forced Convection in Channels and Bundles, S. Kakac and D. B. Spalding, Eds. Hemisphere, USA. 
Johansson, M.T. and Söderström, M. (2014). Electricity generation from low-temperature industrial excess heat - an opportunity for the steel industry. Energy Efficiency 7, 203-215.

Karellas, S., Schuster, A. and Leontaritis, A. (2012). Influence of supercritical ORC parameters on plate heat exchanger design. Applied Thermal Engineering 33-34, 70-76.

Lemmon, E.W., Huber, M.L. and McLinden, M.O. (2010). NIST Standard Reference Database 23: Reference Fluid Thermodynamic and Transport Properties-REFPROP, Version 9.0. Gaithersburg: National Institute of Standards and Technology.

Molina-Thierry, D.P. and Flores-Tlacuahuac, A. (2015). Simultaneous Optimal Design of Organic Mixtures and Rankine Cycles for Low-Temperature Energy Recovery. Industrial \& Engineering Chemistry Research 54, 3367-3383.

Palma-Flores, O., Flores-Tlacuahuac, A. and CansecoMelchor, G. (2015). Optimal molecular design of working fluids for sustainable low-temperature energy recovery. Computers \& Chemical Engineering 72, 334349.

Quoilin, S., Aumann, R., Grill, A., Schuster, A., Lemort, V. and Spliethoff, H. (2011). Dynamic modeling and optimal control strategy of waste heat recovery Organic Rankine Cycles. Applied Energy 88, 2183-2190.

Quoilin, S., Lemort, V. and Lebrun, J. (2010). Experimental study and modeling of an Organic Rankine Cycle using scroll expander. Applied Energy 87, 1260-1268.

Saleh, B., Koglbauer, G., Wendland, M. and Fischer, J. (2007). Working fluids for low-temperature organic Rankine cycles. Energy 32, 1210-1221.

Schuster, A., Karellas, S. and Aumann, R. (2010). Efficiency optimization potential in supercritical Organic Rankine Cycles. Energy 35, 1033-1039.

Sharabi, M., Ambrosini, W., He, S. and Jackson, J.D. (2008). Prediction of turbulent convective heat transfer to a fluid at supercritical pressure in square and triangular channels. Annals of Nuclear Energy 35, 9931005.
Shu, G., Yu, G., Tian, H., Wei, H. and Liang, X. (2014). A Multi-Approach Evaluation System (MA-ES) of Organic Rankine Cycles (ORC) used in waste heat utilization. Applied Energy 132, 325-338.

Sun, J. and Li, W. (2011). Operation optimization of an organic rankine cycle (ORC) heat recovery power plant. Applied Thermal Engineering 31, 2032-2041.

Thulukkanam, K. (2013). Heat exchnager design handbook, 2nd edn. CRC Press, Boca Raton, USA.

Tian, H., Shu, G., Wei, H., Liang, X. and Liu, L. (2012). Fluids and parameters optimization for the organic Rankine cycles (ORCs) used in exhaust heat recovery of Internal Combustion Engine (ICE). Energy 47, 125-136.

Wang, Z.Q., Zhou, N.J., Guo, J. and Wang, X.Y. (2012). Fluid selection and parametric optimization of organic Rankine cycle using low temperature waste heat. Energy 40, 107-115.

Zhang, H.G., Wang, E.H. and Fan, B.Y., (2013). Heat transfer analysis of a finned-tube evaporator for engine exhaust heat recovery. Energy Conversion and Management 65, 438-447.

Zhang, J., Zhang, W., Hou, G. and Fang, F. (2012). Dynamic modeling and multivariable control of organic Rankine cycles in waste heat utilizing processes. Computers \& Mathematics with Applications 64, 908921.

Zhang, J., Zhou, Y., Wang, R., Xu, J. and Fang, F. (2014). Modeling and constrained multivariable predictive control for ORC (Organic Rankine Cycle) based waste heat energy conversion systems. Energy, 66, 128-138. 